\title{
PROGRESS TOWARDS A 1300 NM FIBRE AMPLIFIER
}

\author{
D.W. Hewak
}

\section{Introduction}

Optical fibre amplifiers are key devices for increasing the transmission distance, speed and capacity of optical communication systems. We report on current worldwide progress in the development of glass fibre amplifiers for amplification in the 1.3 micron transmission window. There are three candidates for a practical device for this application, all of which require a glass host which is not silica based. As a consequence, performance and application of these devices does not yet match that of the erbium doped fibre amplifier operating at 1.55 microns. However, the majority of land-based optical fibre operates at wavelengths around $1300 \mathrm{~nm}$ therefore there remains considerable interest for a practical amplifier. Recent trends, such as the development of wavelength-division multiplexing (WDM) systems, has meant that fibre amplifiers must meet a variety of requirements. These include high gain, high output power, a low noise figure, a broad and flat gain spectrum, high reliability, low cost, and compactness.

Candidates for a 1.3 micron fibre amplifier include praseodymium doped fluoride (PDFA) or a similar device based on chalcogenide glasses, both of which have demonstrated amplification though not yet at practical levels; neodymium doped fluoride glasses for which signal gain is possible but severely limited by competing transitions; and dysprosium doped chalcogenide glasses, from which only fluorescent has been demonstrated. In this presentation we review progress in these three variations of the ubiquitous $1300 \mathrm{~nm}$ optical fibre amplifier.

\section{Praseodymium doped fibre amplifiers}

The first demonstration of amplification at 1.3 microns was obtained by a $\mathrm{Pr}^{3+}$-doped $\mathrm{ZrF}_{4}$-based, also know as ZBLAN, fibre. Since then low phonon energy glasses have generated great interest as efficient hosts $[1,2]$. By reducing the phonon or vibrational energies of the glass host, more pump power is made available for amplification. Even so, in a ZBLAN fibre, efficiencies of only $4 \%$ are typical, thus there has been a considerable amount of research on new glass hosts for efficient PDFAs. The suggested hosts are $\mathrm{InF}_{3}$-based system [3], the $\mathrm{InF}_{3} / \mathrm{GaF}_{3}$-based system [4], the $\mathrm{PbF}_{2} / \mathrm{InF}_{3}$-based system [5], mixedhalide glasses [6], chalcogenide glasses such as Ga-La-S [7], Ga-Na-S [8], and As-S [9]. The InF $\mathrm{F}_{3}$-based fluoride glass family is the most promising candidate as the glass host for the next generation of PDFAs in terms of maximizing gain whilst still retaining a practical fibre material. Higher gains can be achieved in a chalcogenide, or sulphide-based glass fibre, however fibre losses in these materials remain several orders of magnitude higher than in a fluoride host. In all these materials, the key issue in developing an efficient PDFA is to reduce the losses of the fibres.

Amplification has been recently demonstrated in single-mode $\mathrm{InF}_{3}$-based fibres fabricated by using a modified jacketing method [10]. The preforms were prepared by the conventional suctioncasting method. Raw materials $\mathrm{InF}_{3}$ and $\mathrm{GaF}_{3}[3,5]$ were purified by solvent extraction with acetylac-

\section{Optoelectronics Research Centre \\ University of Southampton \\ Southampton UK}


etone in benzene. Mixtures of the core and cladding materials and $\mathrm{NH}_{4} \mathrm{~F} \cdot \mathrm{HF}$ were melted at $850^{\circ} \mathrm{C}$ in vitreous carbon crucibles. The melts were cast into metal moulds to produce preforms and jacketing tubes. The transmission loss spectra were measured using the cutback technique. The signal gain dependence on pump power was measured using the fabricated $\operatorname{Pr}^{3+}$-doped fibre. The fibre was buttjoined to wavelength-division-multiplexing couplers and forward pumped using a Ti:sapphire laser. The pumping wavelength was $1.015 \mu \mathrm{m}$, and the signal wavelength and signal level were $1.30 \mu \mathrm{m}$ and $30 \mathrm{dBm}$, respectively.

Single-mode fibres with $\Delta \mathrm{n}$ values of up to $3.7 \%$ were fabricated using the $\mathrm{InF}_{3}$-based system [3] and to $6.6 \%$ using the $\mathrm{PbF}_{2} / \mathrm{InF}_{3}$-based system [5]. A typical transmission loss spectrum is shown in Fig 1. The large peaks around wavelengths of 0.6 and $1.0 \mu \mathrm{m}$ are caused by $\mathrm{Pr}^{3+}$. The small peak at $0.8 \mu \mathrm{m}$ is due to the cutoff of the first high-order mode. These loss characteristics indicate that the losses of the $\mathrm{InF}_{3}$-based fibres approach the practical level required for fibre amplifiers.

Figure 2 shows the internal small signal gain dependence on the pump power for $20 \mathrm{~m}$ long and $19 \mathrm{~m}$ long single-mode fibres with $\Delta \mathrm{n}$ values of 3.7 and $6.6 \%$ respectively [11]. The dependence with

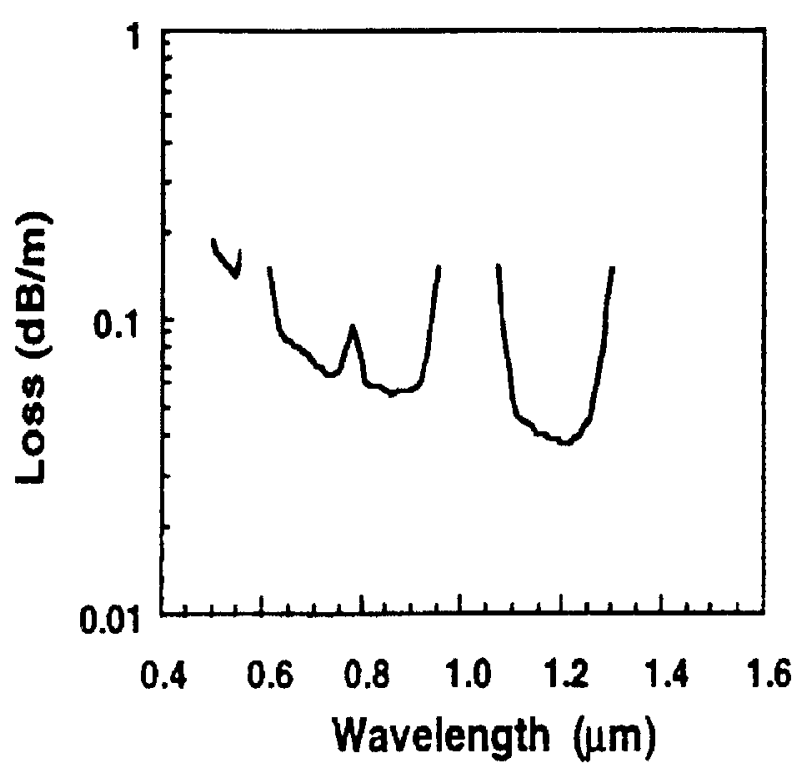

Figure 1 A typical transmission loss spectrum for $\mathrm{InF}_{3}$-based glass

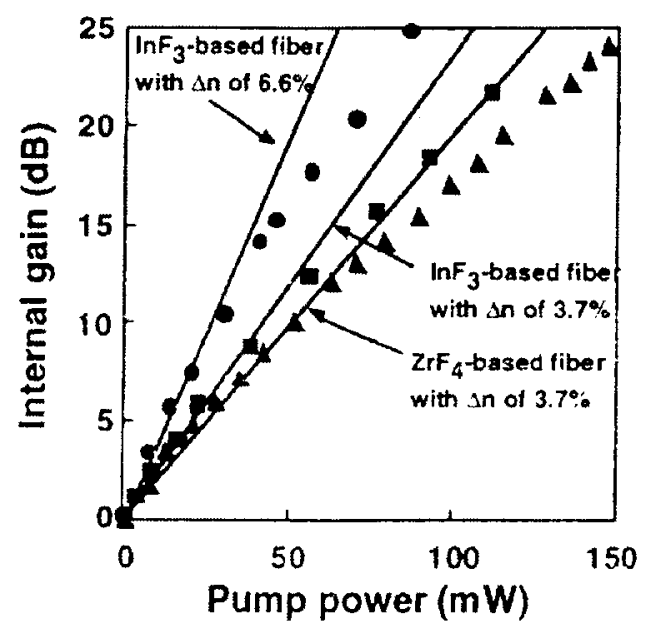

Figure 2 Internal small signal gain dependence on the pump power for $20 \mathrm{~m}$ and $19 \mathrm{~m}$ long single-mode fibers with $\Delta \mathbf{n}$ values of 3.7 and $6.6 \%$ respectively

the most efficient $\mathrm{ZrF}_{4}$-based fluoride fibre with a $\Delta \mathrm{n}$ of $3.7 \%$ is also shown for comparison [12]. An internal small signal gain of $28.2 \mathrm{~dB}$, corresponding to a net gain of $20 \mathrm{~dB}$, for a fibre with a $\Delta \mathrm{n}$ of $6.6 \%$ was achieved at a pump power of $100 \mathrm{~mW}$. This net gain is nearly double that of the most efficient $\mathrm{ZrF}_{4^{-}}$ based $\mathrm{Er}^{3+}$-doped fibre. The gain coefficient was increased from 0.18 to 0.36 by increasing the $\Delta \mathrm{n}$ from 2.5 to $6.6 \%$ for $\mathrm{InF}_{3}$-based fibres. It is clear that $\mathrm{InF}_{3}$-based fibre achieved gain coefficients about 1.3 times higher that $\mathrm{ZrF}_{4}$-based fibre with the same $\Delta \mathrm{n}$ value.

\section{Neodymium doped fibre amplifier}

Among the first devices proposed for amplification at 1300nm were $\mathrm{Nd}^{3+}$-doped ZBLAN which provided gain peaks at $1345 \mathrm{~nm}$ however gain was limited to $6 \mathrm{~dB}$ due to a competing transition at 1050 $\mathrm{nm}$ which robs the amplifier of power [13]. Only with suppression of this amplified spontaneous emission (ASE) can the full potential of a $\mathrm{Nd}^{3+}$ amplifier be realized. Zemon showed that fluoroberyllate 
glass is superior to fluorozirconate, with gain predicted from 1300 to $1320 \mathrm{~nm}$ with the appropriate ASE filtering. These glasses however were never drawn into fibre and questions were raised due to their toxicity [14]. Modelling to establish fundamental limits of the performance of a $\mathrm{Nd}^{3+}$-doped fibre amplifier were performed by Dakss and Miniscalco [15]. They concluded that ESA is the critical parameter for determining amplifier efficiency and that even without ESA, a linear $\mathrm{Nd}^{3+}$ fibre amplifier is an order of magnitude less efficient that an $\mathrm{Er}^{3+}$ amplifier. This suggests that $\mathrm{Nd}^{3+}$ may not do well as preamplifiers and in-line amplifiers. However, because of high photon conversion efficiencies, at large signal powers, they may perform well as power amplifiers in glasses with minimal ESA.

There are some advantages in favour of a $\mathrm{Nd}^{3+}$-doped $1300 \mathrm{~nm}$ amplifier as compared to a $\mathrm{Pr}^{3+}$ doped device. The convenient pump wavelength of $800 \mathrm{~nm}$ for which pump lasers are readily available and inexpensive, and high doping concentrations which allow a short and compact device are important attributes. Modelling predicts gains of $20 \mathrm{~dB}$ for $100 \mathrm{~mW}$ of pump power with optimum fibre parameters. For most glass hosts, $\mathrm{Nd}^{3+}$ emission is at too long a wavelength to cover even the central region of the window. In silica, gain is limited to wavelengths greater than $1400 \mathrm{~nm}$ due to excited state absorption. This process can be reduced by moving to more ionic glass host and less rigidity of the glass matrix.

At the ORC, a novel family of fluoroaluminate (AIF) glasses have been identified as at promising host for an efficient and inexpensive $\mathrm{Nd} 3+$-doped glass amplifier. The strong absorption of $\mathrm{Nd}^{3+}$ at $800 \mathrm{~nm}(170 \mathrm{~dB} / \mathrm{m} / 1000 \mathrm{ppm})$ and the strong solubility of the ion in AIF glass (up to $4 \times 10^{4} \mathrm{ppm}$ ) suggest a short device of $\sim 2 \mathrm{~cm}$ unlike the $10 \mathrm{~m}$ needed in $\operatorname{Pr} 3+$-doped amplifiers.

A fibre based on AlF glass has been fabricated with a numerical aperture (NA) of 0.23 , core diameter of $8 \mu \mathrm{m}$ and loss at $1300 \mathrm{~nm}$ of $\sim 100 \mathrm{~dB} / \mathrm{m}$. Three-centimeter lengths of the fibre were mounted inside a capillary and both end faces polished. The fibre was then pumped by a Ti:sapphire laser operating around $800 \mathrm{~nm}$. In order to minimise any thermal problem associated with the high pump powers $(>300 \mathrm{~mW})$, the pump laser was chopped with a low mark/space ratio (1:10). For measuring the gain spectrum of the $\mathrm{Nd}^{3+}$-doped AIF fibres, a $1300 \mathrm{~nm}$ LED signal source was used and chopped at $\sim 300 \mathrm{~Hz}$. This allows a lock-in amplifier to be used in the detection system and allows discrimination between the signal and any ASE or fluorescence. The gain is then simply the ratio of the measured signal

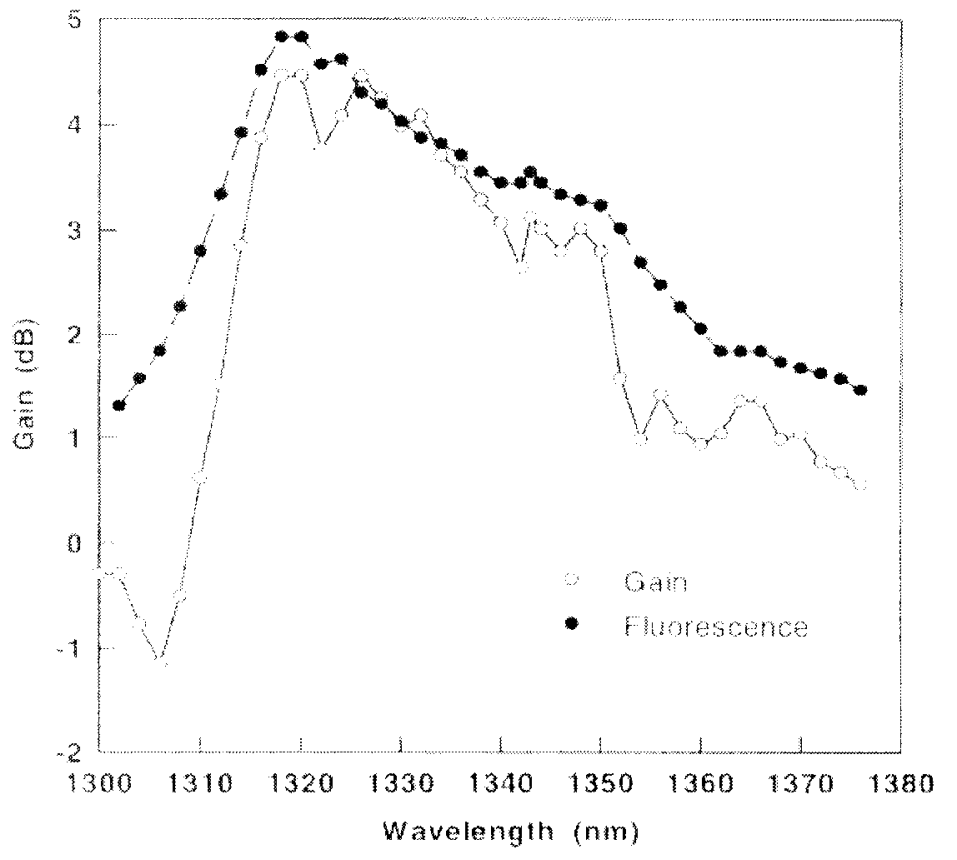

Figure 3 Gain Spectrum of $\mathrm{Nd}^{3+}$-doped AIF glass with the pump and off. The end face of the fibre was angle polished at $\sim 150$ in order to suppress the lasing at $1049 \mathrm{~nm}$.

The measured gain spectrum is shown in figure 3 and is compared with the measured fluorescence spectrum for the same $\mathrm{Nd}^{3+}$-doped fibre. Significantly, the two spectra have very similar peak wavelengths, indicating that negligible ESA occurs at this wavelength. The peak wavelength at $1317 \mathrm{~nm}$ corresponds to the wavelength of zero dispersion in UK installed fibres. At shorter wavelengths the gain spectrum falls off more quickly than the fluorescence, indicating that significant amounts of ESA are present in this region of the 
spectrum. The laser emission spectrum for this fibre occurs at the peak of the gain curve at $1317 \mathrm{~nm}$. This was measured by butting two high reflecting mirrors (reflectivity $>80 \%$ at wavelengths between $1200-1400 \mathrm{~nm}$ and $<10 \%$ between $900-1100 \mathrm{~nm}$ ) to both of the fibre ends. This lasing wavelength is significantly shorter than that achieved in either fluorophosphate [16] or fluorozirconate [17] fibres again indicative of reduced ESA.

\section{Dysprosium doped fibre amplifier}

Although amplification has yet to be demonstrated, the potential of dysprosium-doped low phonon energy glasses to provide an attractive alternative to neodymium and praseodymium has been shown. Through calculation of the radiative proper ties and measurement of the fluorescence emission and lifetimes the radiative quantum efficiency at $1.3 \mu \mathrm{m}$ has been determined

The fluorescence spectrum in the region of $1300 \mathrm{~nm}$ is shown in figure 4 . This is obtained by pumping at 814 or $914 \mathrm{~nm}$. Emission which peaks at $1317 \mathrm{~nm}$ with a half width of $83 \mathrm{~nm}$ is observed, predominantly from the ${ }^{6} \mathrm{H}_{9 / 2}$ energy level. The total lifetime of this level was measured to be $59 \mathrm{~ms}$, compared to a calculated radiative lifetime of $203 \mu \mathrm{s}$. Taking into account the branching ratios of this level yields a total radiative quantum efficiency of $27 \%$ [18].

As in a $\mathrm{Pr}^{3+}$-doped amplifier, nonradiative de-excitation contributes to the decay mechanism

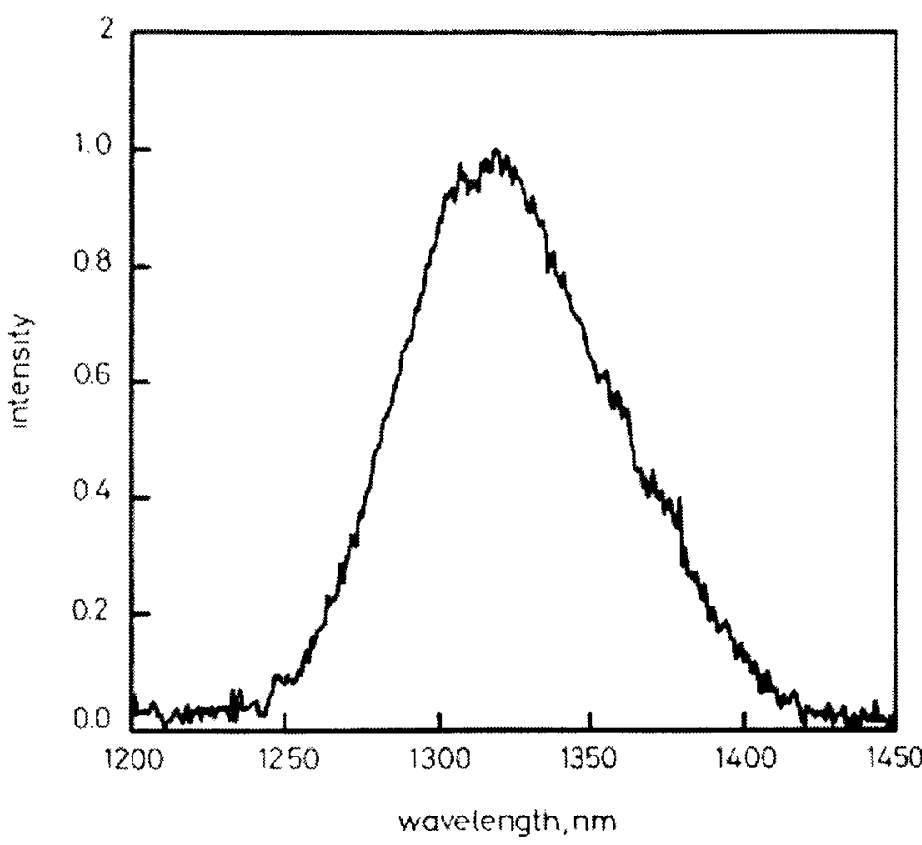

Figure 4 Fluorescence Spectrum of $\mathrm{Dy}^{3+}$-doped Ga:La:S glass largely through multiphonon decay to the lower lying levels. This value compares well with the $17 \%$ efficiency estimated using a radiative rate calculated from measured absorption and emission spectra [18]. For a three-level system, the gain per unit absorbed pump power can he assessed from the product of the peak emission cross-section and the measured lifetime. From the calculated radiative rate and measured fluorescence spectrum, an emission cross- section of $3.8 \times 10^{-20} \mathrm{~cm}^{2}$ was calculated. With a lifetime of $59 \mu \mathrm{s}$, this yields a $\sigma \tau$ product of $-220\left(\times 10^{-26} \mathrm{~cm}^{2} \mathrm{~s}\right)$, compared to 250 for $\mathrm{Pr}^{3+}$-doped $\mathrm{Ga}: \mathrm{La}: \mathrm{S}, 45$ for $\mathrm{Pr}^{3+}$-doped ZBLAN and 160 for $\mathrm{Nd}^{3+}$-doped ZBLAN.

In addition to pumping at 814 and 914 $\mathrm{nm}$, in-band pumping at $1.25 \mu \mathrm{m}$, may he feasible. Most significant here is that the absorption cross-section of $\mathrm{Dy}^{3+}$ when pumped at $1.25 \mu \mathrm{m}$ is -20 times greater than $\mathrm{Pr}^{3+}$ pumped at $1.01 \mu \mathrm{m}$. This suggests that radically shorter devices may be possible, relaxing the tolerances on fibre background loss. 


\section{Conclusions}

There are several schemes which will allow optical fibre amplification around $1300 \mathrm{~nm}$. At the present time, $\operatorname{Pr}^{3+}$-doped fluoride and chalcogenide glasses have been drawn into fibre and prototype devices demonstrated. $\mathrm{Nd}^{3+}$-based devices, which require different glass host properties, remain viable although attention must be paid to competing transition. Dy ${ }^{3+}$-based glasses show promise and are attracting more interest.

\section{Acknowledgements}

The author acknowledges the research of Beth Taylor, Yvonne West and Roger Moore to work on AlFbased glasses. The contributions of Dom Brady, John Tucknott, Thorsten Schweizer and Bill Brocklesby to our programme on Ga:La:S glass is also gratefully appreciated. This work was sponsored in part by the EPSRC and DTI through the LINK Photonics Programme.

\section{References}

[1] Y. Ohishi, T. Kanamori, T. Kitagawa, S. Takahashi, E. Snitzer and G.H. Sigel [Opt. Lett vol.16(1991)p.1747.]

[2] Y. Ohishi, T. Kanamori, T. Nishi, Y. Nishida and S. Takanhashi [proc Int. Cong. Glass, Madrid (1992) p.73.]

[3] Y. Nishida, Y. Ohishi, t. Kanamori, Y. Teranuma, K. Kobayashi and S. Sudo [proc 19th Ero. Conf. Optical Communication, Montreux vol. 1 (1993) p.34.]

[4] H. Yanagita, K. Itoh, E. Ishikawa, H. Aoki and H. Toratani [Tech. Dig. of OFC'95, Washington, DC (1995) PD2.]

[5] Y. Nishida, T. Kanamori, Y. Ohishi, M. Yamada, K. Kobayashi and S. Sudo [Tech. Dig. of OAA'96, washington, DC (1996) PD3.]

[6] M.A. Newhouse, B.G. Aitken, R.F. Bartholomew, L.J. Button and N.F. Borrelli [Tech. Dig. of OAA'93, Washington, DC (1993) p.248.]

[7] D.W.Hewak, J.A.Madeiros-Neto, B.N.Samson, R.S.Brown, K.P.Jedrzejewski, J.Wang, E Taylor, R.I.Laming, G.Wylangowski \& D.N.Payne [IEEE Phot. Tech. Lett. 1994 Vol.6 (5) pp.609-612 ].

[8] H. Tawarayama, et al [Tech. Dig. of OAA'97, Washington, DC (1997) PD1.]

[9] Y. Ohishi, A. Mori, T. Kanamori, K. Fujiura and S. Sudo [Appl. Phys. Lett. vol.65 (1994) p.13.]

[10] T. Kanamori, et al [J. Non-Cryst. Solids vol.213\&214 (1997) p. 121 ]

[11] T. Shimada, et al [Electron. Lett. vol.33 (1997) p.1972]

[12] Y. Ohishi, T. Kanamori, Y.Terunuma, M. Shimizu, M. Yamada and S. Sudo [IEEE Photon. Tech. Lett. 6 (1994) p.195]

[13] M.C. Brierly, S. Carter, P.W. France and J. Pederson [ Electronics Lett 26 (1990) p. 329 ]

[14] S. Zemon GTE Labororatories Inc. Private Communication

[15] M.L. Dakss and W.J. Miniscalco [Photon. Tech. Lett. 2 (1990) p. 650 ]

[16] H. Ishikawa, T. Aoki, Y. Yamashita, Y. Asahara [ Electron. Lett., 28 (1992) 1492]

[17] W. J. Miniscalco et al [ European Patent Application 0320665-A2 ]

[18] D.W.Hewak, B.N.Samson, J.A.Medeiros-Neto, R.I.Laming, D.N.Payne [ Electron. Lett. 1994 Vol.30 (12) pp.968-969 ] 